\title{
El hombre empresa como proyecto ético político. Lecturas de Michel Foucault
}

\section{The enterprise man as an ethic-politic project. Readings of Michel Foucault}

Dr. (c) Adán Salinas ${ }^{1}$

\begin{abstract}
Resumen:
El artículo pretende explorar la categoría de hombre-empresa, que Foucault propuso como uno de los dispositivos o interfaces claves del poder en el contexto del neoliberalismo. A través de esta categoría se muestra una particular forma de poder sobre la vida, o biopoder, que es distinto al tipo de poder de la sociedad disciplinaria, aunque tiene relaciones de continuidad con este último. En tal sentido el artículo maneja la hipótesis de la superposición o coexistencia de las formas del poder, en contra de las hipótesis más extendidas, que entienden la biopolítica o como una superación de las sociedades disciplinarias o como una sofisticación de la misma. El artículo remite constantemente a las formas del neoliberalismo chileno como punto de referencia para entender las tensiones del biopoder.
\end{abstract}

Palabras clave: hombre empresa - biopoder - sociedad - biopolítica - neoliberalismo.

\begin{abstract}
:
The article pretends to explore the man-enterprise category that Foucalt proposed as one of the key mechanisms or interfaces of power in neoliberalism context. Through this category, a special way of power over life or biopower is revealed, which is different to the type of power in disciplinary society, although it has some continuity connections with the later. In this sense, this paper deals with the hypothesis of superposition or coexistence of power forms, against of more extensive hypotheses that understand the biopolitics or as an overcoming of the disciplinary societies or as a sophistication of itself. The article refers constantly to the Chilean neoliberalism ways like a reference to comprehend the tensions of the biopower.
\end{abstract}

Key words: Enterprise man - biopower - society - biopolitics - neoliberalism

\footnotetext{
1 Chileno. Profesor de Filosofía, y Licenciado en Educación por la Universidad Católica Silva Henríquez. Magíster en Filosofía, con mención en filosofía moral y política, por la Universidad de Chile. Master en estudios avanzados en Filosofía, por la Universidad Complutense de Madrid. Se ha desempeñado como académico en la UCSH, y directivo de la Fundación Chilenter. Actualmente es editor de la revista HIBRYS de CENALTES y realiza estudios doctorales en la Universidad Complutense de Madrid, mediante beca CONICYT.
} 


\section{Introducción}

Hay proyectos ético-políticos dominantes, previos incluso a la formulación de cualquier proyecto personal. En cierto sentido, esto es lo que explicita Michel Foucault, cuando muestra la relación entre poder y subjetividad, vale decir, la forma en que el poder condiciona y genera subjetividad, actuando sobre la vida de los sujetos, sus formas de hacer, sus modos de pensar y su capacidad de pensarse y situarse ante el mundo.

Podemos considerar entonces, que un proyecto ético-político, es un proyecto de subjetividad. Una forma, en este caso preconcebida, un molde que se aplica a la vida de los sujetos. Estos modos en que el poder actúa sobre los sujetos, creando formas particulares de subjetividad, es lo que podemos llamar en términos generales un proceso de subjetivación.

Cualquier proyecto de sí mismo, implica reconocer tales formas previas de subjetivación. Por el contrario, cuando no se logra reconocer tales formas previas, que actúan incluso sobre la propia subjetividad, fácilmente se considera a los proyectos dominantes, como proyectos necesarios e incontestables. La posibilidad de tener un proyecto de sí mismo implica, entonces, reconocer tales proyectos dominantes en el contexto social y político. Ante tal reconocimiento, es posible decidir en mayor o menor grado insertarse en tal proyecto, o por el contrario, decidir -nuevamente, en menor o mayor grado-, no insertarse, resistir, o intentar hacerlo.

El curso que dictó Foucault en el Colegio de Francia en 1978-1979, llamado El Nacimiento de la biopolítica, nos ofrece una categoría interesante para pensar el problema de los proyectos de subjetividad, o proyectos ético-políticos dominantes en la actualidad; se trata de la categoría de hombre-empresa. Es necesario, en todo caso, situar esta idea del hombre-empresa, en el análisis más amplio que realizó Foucault sobre el poder y la subjetividad. Por lo tanto, me permito, a modo de introducción, una breve descripción de las ideas clave sobre 
la sociedad disciplinaria. Seguramente algún especialista en el trabajo de Foucault podrá encontrar una serie de deficiencias en tal síntesis. No obstante, me parece un gesto necesario, para no proponer una lectura parcializada del problema biopolítico. Del mismo modo, me parece importante ejemplificar algunos de los temas implicados a partir de la realidad chilena, tanto por su papel en la actual instalación del neoliberalismo en vías de globalización; como por la necesidad de acercar al lector local, al problema biopolítico. Se trata de ejemplos desarrollados desde la visión de un ciudadano, y no de un especialista en políticas públicas o economía. Por lo cual tales ejemplos pueden ser contrastados, complementados y -no me cabe duda- en algún sentido refutados, por distintas perspectivas de análisis surgidas de estos campos. No obstante, en su conjunto me parece que son ejemplos válidos y que grafican algunos aspectos fundamentales de lo que aquí está puesto en discusión, que además de ser un tema de actualidad filosófica tiene una particular contingencia, especialmente en Chile.

\section{Las formas de poder en la sociedad disciplinaria}

Como es de conocimiento extendido, Foucault desarrolló un amplio y valioso análisis de las formas de poder y subjetividad en lo que llamó las sociedades disciplinarias. Tales sociedades operan bajo la lógica de la normalización, que en lo medular aplica el principio de que todos los sujetos deben vivir bajo un mismo patrón de conducta ${ }^{2}$. Patrón que sirve tanto para homogenizar, como para clasificar ${ }^{3}$. Por lo tanto, las sociedades

\footnotetext{
2 "De una manera global puede decirse que las disciplinas son unas técnicas para garantizar la ordenación de las multiplicidades humanas". FOUCAULT, Michel. Vigilar y Castigar. Nacimiento de la Prisión. Trad. Aurelio Garzón del Camino. Siglo XXI. Buenos Aires. 1976. $1^{\text {a }}$ Reimpresión. 2002. Pág. 221.

3 "Como la vigilancia, y con ella la normalización, se torna uno de los grandes instrumentos de poder al final de la época clásica. Se tiende a sustituir o al menos a agregar a las marcas que traducían estatutos, privilegios, adscripciones, todo un juego de grados de normalidad, que son signos de adscripción a un cuerpo social homogéneo, pero que tienen en sí mismos un papel de clasificación, de jerarquización y de distribución de los rangos. En un sentido, el poder de normalización obliga a la homogeneidad; pero individualiza al permitir las desviaciones, determinar los niveles, fijar las especialidades y hacer útiles las
} 
disciplinarias desarrollan una serie de estrategias interrelacionadas para provocar que el efecto de normalización efectivamente se lleve a cabo. La articulación de tales estrategias implica la acción de instituciones, la producción de saberes, la implementación de procedimientos, es decir, un conjunto de elementos muy diversos, que no obstante actúan bajo ciertos principios comunes. Tales articulaciones constituyen lo que Foucault llamó dispositivos. Los dispositivos, funcionan tanto de manera preventiva, pero especialmente coactiva, a través del castigo o disciplinamiento de las conductas que podrían considerarse desviadas, es decir, que no se ajustan a los patrones de conducta, asumidos como normales. La sociedad disciplinaria, desarrolla entonces una función amplia de ortopedia social, que en este caso hay que entender como corrección de lo desviado, anormal o indeseable ${ }^{4}$.

Las estrategias de estos procesos de normalización de los sujetos se llevan a cabo, principalmente, a través de los lugares de encierro, cuyo modelo es la cárcel; pero que también se puede reconocer en otro tipo de instituciones como el hospital, el asilo y el manicomio, la fábrica y la escuela, el regimiento. En estos lugares funcionan procesos preventivos y coactivos. Si nos detenemos en ellos, es más reconocible la función preventiva en la escuela, el regimiento y la fábrica; y la función coactiva en la cárcel o el manicomio.

Los mecanismos disciplinarios prestan una atención especial a los cuerpos, por tal razón, Foucault califica estos procedimientos, también bajo el rótulo de 'anatomopolítica', que en principio refiere a la acción del poder sobre los cuerpos individuales.

A estos métodos que permiten el control minucioso de las operaciones del cuerpo, que garantizan la sujeción cons-

diferencias ajustando unas a otras". FOUCAULT, Michel. Vigilar y Castigar. Op. Cit. Pág. 189.

4 "Entramos así en una edad que yo llamaría de ortopedia social. Se trata de una forma de poder, un tipo de sociedad que yo llamo sociedad disciplinaria por oposición a las sociedades estrictamente penales que conocíamos anteriormente". FOUCAULT, Michel. La verdad y las formas jurídicas. Trad. Enrique Lynch. Gedisa. Barcelona. 1996. Pág. 98. 
tante de sus fuerzas y les imponen una relación de docilidad-utilidad, es a lo que se puede llamar las "disciplinas". Muchos procedimientos disciplinarios existían desde largo tiempo atrás, en los conventos, en los ejércitos, también en los talleres. Pero las disciplinas han llegado a ser en el trascurso de los siglos XVII y XVIII unas fórmulas generales de dominación. Distintas de la esclavitud (...) Distintas también de la domesticidad (...) Distintas del vasallaje (...) Distintas también del ascetismo y de las "disciplinas" de tipo monástico (...) El momento histórico de las disciplina es el momento en que nace un arte del cuerpo humano (...) El cuerpo humano entra en un mecanismo de poder que lo explora, lo desarticula y lo recompone. Una "anatomía política", que es igualmente una "mecánica del poder", está naciendo. ${ }^{5}$

Los mecanismos de las disciplinas implican una innovación en las formas de dominación, su minuciosidad, los efectos de docilidad-utilidad buscados, implican además una relación particular con los saberes. Resulta interesante que, para que tales formas de normalización aparezcan como legítimas, y por lo tanto reciban consentimiento de la sociedad en su conjunto, es necesario que funcione una idea de lo normal, socialmente aceptada y legitimada. De modo que la lógica de la legitimación opera bajo una racionalidad como la siguiente: "si un sujeto es anormal, entonces es válido someterlo a las prácticas de encierro, con sus consecuentes formas de castigo físico y deprivación social e intelectual, puesto que esto persigue volverlo normal, y así pueda interactuar normalmente con el resto de los sujetos". Ahora bien, es interesante que la idea de lo normal, que aquí está en juego, reciba una legitimación no sólo moral, sino también, científica. Puesto que, así presentada, la idea de lo normal es fundamentalmente política. En este sentido, la perspicacia de Foucault es rotunda al mostrar que los saberes de las llamadas ciencias humanas permiten establecer una idea

5 FOUCAULT, Michel. Vigilar y Castigar. Op. Cit. Págs. 140-141. 
de lo normal, con legitimidad científica; de tal modo que el desarrollo, principalmente en el siglo XIX ${ }^{6}$, de saberes como la sicopatología o la criminología, y posteriormente, ciertas formas generales de sicología educacional y conductual, y ciertas perspectivas sociológicas y antropológicas, ayudan o permiten la consolidación de una idea de lo normal, científicamente establecida ${ }^{7}$. En tal contexto cultural, además, una idea "científicamente establecida" se transforma por tal estatuto, en una idea legítima en sí misma. De este modo, la normalización de los sujetos es llevada a cabo a través de ciertos dispositivos, que incluyen una idea de normalidad legitimada moral y científicamente . $^{8}$

Entre las tecnologías específicas a las que Foucault ha prestado atención, en su análisis de las sociedades disciplinarias, destaca la figura del panóptico, que ha sido recepcionada muy ampliamente. En principio, se trata de un modelo arquitectónico, que grafica una intención social general de vigilancia. El panóptico es un tipo de edificio, propuesto por Bentham, con una forma circular, que permite mantener vigilados los distintos lugares desde un solo punto central ${ }^{9}$. Tal edificio estaba

6 "Me gustaría mostrar en particular cómo puede formarse en el siglo XIX, un cierto saber del hombre, de la individualidad, del individuo normal o anormal, dentro o fuera de la regla; saber éste que, en verdad, nació de las prácticas sociales de control y vigilancia". FOUCAULT, Michel. La verdad y las formas jurídicas. Op. Cit. Pág. 14.

7 "Tenemos así, a diferencia del gran saber de indagación que se organizó en la Edad Media a partir de la confiscación estatal de la justicia y que consistía en obtener los instrumentos de reactualización de hechos a través del testimonio, un nuevo saber totalmente diferente, un saber de vigilancia, de examen, organizado alrededor de la norma por el control de los individuos durante toda su existencia. Esta es la base del poder, la forma del saber-poder que dará lugar ya no a grandes ciencias de observación como en el caso de la indagación, sino a lo que hoy conocemos como ciencias humanas: Psiquiatría, Psicología, Sociología, etcétera". FOUCAULT, Michel. La verdad y las formas jurídicas. Op. Cit. Pág. 100.

8 "Es éste un saber que no se caracteriza ya por determinar si algo ocurrió o no, sino que ahora trata de verificar si un individuo se conduce o no como debe, si cumple con las reglas, si progresa o no, etcétera. Este nuevo saber no se organiza en torno a cuestiones tales como "¿se hizo esto?, ¿quién lo hizo?»; no se ordena en términos de presencia o ausencia, existencia o no existencia, se organiza alrededor de la norma, establece qué es normal y qué no lo es, qué cosa es incorrecta y qué otra cosa es correcta, qué se debe o no hacer". FOUCAULT, Michel. La verdad y las formas jurídicas. Op. Cit. Pág. 100.

9 "El Panóptico era un sitio en forma de anillo en medio del cual había un patio 
pensado inicialmente para la construcción carcelaria, aunque es posible reconocer su influencia en la construcción de fábricas y escuelas. En cierto sentido, la figura de la vigilancia sobre cada individuo, grafica una forma general de racionalidad política, que se relaciona con lo que Foucault llamará policía, vale decir, el conjunto organizado de estrategias que tienen como objeto imponer patrones de normalización a los individuos.

Estas formas de poder de la sociedad disciplinaria, pueden considerarse formas "hoscas", altamente reconocibles y por lo mismo fácilmente denunciables, donde el poder se ejerce individualmente, y no se permiten las diferencias. Se trata de estrategias uniformantes, que proceden muchas veces por el castigo físico, con características represivas, donde diversas instituciones juegan un papel de la mayor importancia: el Estado, el ejército, la fábrica, las iglesias, la escuela, la universidad. Foucault propuso distintas coordenadas cronológicas para situar las sociedades disciplinarias, por lo cual no es conveniente proponer cortes exactos. Pero en términos generales, habría que pensar que algunos rudimentos de tales formas de poder están presentes ya en el sigo XVI, aunque el siglo XVII atestigua su inicio generalizado. El siglo XVIII se trataría de un siglo altamente disciplinario, y con ciertas transformaciones, el siglo XIX también estaría atravesado por estas formas disciplinarias. Además Foucault señala una cierta dirección de transformación de las formas de poder, o una cierta "salida de las sociedades disciplinarias", asunto al que

con una torre en el centro. El anillo estaba dividido en pequeñas celdas que daban al interior y al exterior y en cada una de esas pequeñas celdas había, según los objetivos de la institución, un niño aprendiendo a escribir, un obrero trabajando, un prisionero expiando sus culpas, un loco actualizando su locura, etc. En la torre central había un vigilante y como cada celda daba al mismo tiempo al exterior y al interior, la mirada del vigilante podía atravesar toda la celda; en ella no había ningún punto de sombra y, por consiguiente, todo lo que el individuo hacía estaba expuesto a la mirada de un vigilante que observaba a través de persianas, postigos semicerrados, de tal modo que podía ver todo sin que nadie, a su vez, pudiera verlo. Para Bentham, esta pequeña y maravillosa argucia arquitectónica podía ser empleada como recurso para toda una serie de instituciones". FOUCAULT, Michel. La verdad y las formas jurídicas. Op. Cit. Pág. 99. 
también alude Deleuze, quien afirma que el auge de las sociedades disciplinarias fue a comienzos del siglo XX. Esto último, sugiere por tanto que las sociedades disciplinarias están en repliegue, o ya se han acabado o están en franco retroceso. Me parece que conviene seguir en parte tal sugerencia, como se verá a continuación; Foucault analiza toda una forma de poder sobre la vida, que es muy diverso a las disciplinas, lo cual atestigua ya su retroceso. Sin embargo, la hipótesis que mantengo al respecto es que se trata de lógicas superpuestas, más que procesos de reemplazo, por lo cual esta "salida" de las sociedades disciplinarias, indicaría una dirección, un rumbo, pero no su clausura. Perdóneseme, entonces, este esbozo sobre las sociedades disciplinarias, que acabo de garabatear. Para un lector experto o iniciado en la temática, probablemente sea tan discutible como innecesario. No obstante, supongo que para más de algún lector serán imprescindibles, estos garabatos previos.

\section{La biopolítica y las nuevas formas de producción de subjetividad}

La tecnología de poder biopolítico conseguirá instaurar mecanismos que tendrán funciones muy diversas de las que eran propias de los mecanismos disciplinarios. De hecho, en los mecanismos instaurados por la biopolítica, se tratará en primer lugar de previsiones, estimaciones, estadísticas, medidas globales, pero se tratará también de modificar, no tanto un fenómeno particular o un determinado individuo, como intervenir a nivel de las determinaciones de los fenómenos generales. ${ }^{10}$

Además de los mecanismos disciplinarios, a los que acabo de referirme, Foucault propondrá el surgimiento de nuevas formas de poder sobre los sujetos, que son distintas a las anteriores aunque mantienen

10 FOUCAULT, Michel. Genealogía del Racismo. Trad. Alfredo Tzveibel. Altamira. La Plata, Argentina. 2001. Pág. 199. 
una conexión íntima con ellas, y que rotula bajo el término general de biopolítica.

La noción de Biopolítica en Foucault, no es un término unívoco ${ }^{11}$, por el contrario señala una serie de modulaciones de las formas de subjetivación del poder, en cuanto el poder se ejerce, en la época moderna, como poder sobre la vida, o biopoder. Se puede postular una serie de diferencias entre las formas que asumen las tecnologías biopolíticas; no obstante, me parece que, para el presente artículo, es necesario delimitar dos grandes modalidades de este tipo de poder sobre la vida. La primera de ellas tiene una relación más estrecha

\footnotetext{
11 Así lo muestran los usos y transformaciones que el término biopolítica asume en los cursos del colegio de Francia. Foucault utiliza por primera vez el término "biopolítica" en las conferencias de Río de Janeiro en 1974. Aunque frente al término no hay una explicación de su alcance, se trata de un uso adjetivante, equivalente a una "expresión". El término sólo es usado en una afirmación al interior de la conferencia. Se trata de un uso enfatizante y de un recurso retórico, más que de un concepto clave. Cfr. FOUCAULT, Michel. Nacimiento de la Medicina Social. En Estrategias de Poder, Obras esenciales, Volumen II. Trad. Fernando Álvarez Uría, Julia Varela. Paidós. Barcelona-Buenos Aires-México. 1999. Pág. 366. Posteriormente en el curso de 1975-1976, incluirá además del término biopolítica, el término biopoder. En este curso se comenzará a gestar una idea de biopolítica, que efectivamente transforma este concepto en una clave de lectura. Aun cuando este curso desarrolla la idea de una biopolítica en relación con las formas de poder totalitario, más cercanas al poder disciplinario. En Seguridad, Territorio, Población, curso de 1977-1978, se comenzará a distinguir con mucha claridad un modelo biopolítico en contraste con un modelo anatomopolítico, es decir una biopolítica que ya no está en relación con las sociedades disciplinarias, sino con nuevas formas de poder. Finalmente, en el curso de 1978-1979, El nacimiento de la biopolítica, Foucault propondrá el referente de comprensión del modelo biopolítico actual, vale decir, el neoliberalismo. Edgardo Castro, quien ha estudiado profundamente el asunto, también comparte esta visión sobre las disputas de sentido que la idea de biopolítica alberga en su interior. "En primer lugar, como acabamos de mostrarlo, es necesario tener en cuenta que no existe en los trabajos de Michel Foucault una única concepción de la biopolítica. En segundo lugar, también hay que tener en cuenta que no sólo no nos encontramos con una concepción única, sino que tampoco hallamos una teoría general al respecto. A diferencia de cuanto pueden sugerir algunos desarrollos actuales sobre la biopolítica, para Foucault no se trata de una categoría general, de carácter historiográfico, sino, más bien, de un concepto que debe mostrar su potencialidad analítica en la minuciosidad de los procesos históricos". CASTRO, Edgardo. Biopolítica: De la Soberanía al Gobierno. En Revista Latinoamericana de Filosofía, Vol. XXXIV. Nº 2. Primavera 2008. Pág. 190-191.
} 
con las estrategias de disciplinamiento, que graficaba anteriormente. Mientras las estrategias disciplinarias se enfocan fundamentalmente sobre la normalización de los individuos en particular, las estrategias biopolíticas se orientan a la población como conjunto, a través de una serie de procedimientos de regulación general. Por lo tanto, su espacio privilegiado no son los lugares de encierro; sino la amplitud del espacio urbano y la sociedad en su conjunto. Este tipo de estrategias son descritas por Foucault, en términos principalmente estadísticobiológicos, vale decir, las preocupaciones biopolíticas se orientan a asuntos como la demografía, la natalidad, las tasas de morbilidad, la higiene pública, los procesos migratorios, la nutrición, el tratamiento de enfermedades, las condiciones de la fuerza de trabajo, entre algunos de los aspectos más notorios ${ }^{12}$. Esto implicará desarrollar una serie de regulaciones generales, sobre el marco general de vida de los sujetos. Si las estrategias disciplinarias eran hoscas y mostraban con mucha claridad su vocación represiva, este otro tipo de estrategias resultan mucho más invisibles. Los Estados deberán desarrollar un conjunto de medidas para asegurar ciertas condiciones biopolíticas, como estrategias migratorias, planes de salud, regulaciones laborales, entre otros; pues una población sana, robusta, fuerte, se convierte en el principal objeto de gobierno para un Estado sano, robusto y fuerte. El término policía, entonces, no designa sólo la actitud central de vigilancia sobre

12 "(...) Decíamos que lo que formó los primeros objetos de saber y los primeros objetivos de control de la biopolítica, fueron esos procesos -como la proporción de los nacimientos y los decesos, la tasa de reproducción, la fecundidad de la población-que, en la segunda mitad del siglo XVIII, estaban, como es notorio, en conexión con todo un conjunto de problemas económicos y políticos. Objetos de saber y objetivos de control de la biopolítica eran pues, en general, los problemas de la natalidad, de la mortalidad, de la longevidad (...) Desde comienzos del siglo XIX, en la época de la industrialización, devienen fundamentales los problemas de los incidentes, de los infortunios, de las enfermedades; los de las diversas anomalías; los del individuo que, llegado a la vejez, se ve expulsado al campo de los incapaces y de los inactivos (...)El último ámbito de intervención (...) toma en consideración las relaciones entre los seres humanos como especie, como seres vivientes, y su ambiente de existencia. Se examinará ahora los efectos elementales del ambiente geográfico, climático, hidrográfico y los problemas conexos... Se trata, en una palabra, del problema de la ciudad." FOUCAULT, Michel. Genealogía del Racismo. Op. Cit. Págs. 196-198. 
los individuos, sino un principio de gobierno de tipo expansivo. Me explico, en un Estado policial, no se trata solamente de diversificar la vigilancia sobre las posibles conductas desviadas de los individuos, o sancionar y aplicar su castigo; sino que el principio de gobierno sobre la vida, se extiende a la sociedad en su conjunto. En un Estado policial, siempre se requiere más gobierno.

La Polizeiwissenschaft desarrollada por los alemanes en el siglo XVIII (...) se basaba siempre en este principio: no se presta una atención suficiente, demasiadas cosas se escapan, dominios demasiado numerosos carecen de regulación y reglamento, el orden y la administración faltan; en síntesis: se gobierna demasiado poco. ${ }^{13}$

No se puede dejar al azar o al libre arbitrio, ni la nutrición de los niños, ni la preparación física de los jóvenes, ni el tratamiento sanitario de los viejos; por otra parte, tampoco puede quedar sin gobierno la conformación de la ciudad, las oleadas migratorias, o los procesos de abastecimiento. En un extremo de esta visión, el Estado deberá vigilar los aspectos raciales, los objetos de la cultura, y las consideraciones eugenésicas. Se trata de una biopolítica realizada bajo una particular racionalidad política, que Foucault designa como razón de Estado. "Gobernar, según el principio de la razón de Estado, es actuar de tal modo que el Estado pueda llegar a ser sólido y permanente, pueda llegar a ser rico, pueda llegar a ser Fuerte frente a todo lo que amenaza con destruirlo"14. Ahora bien, este tipo de biopolítica de la razón de Estado, coincide cronológicamente con las estrategias disciplinarias. Tal conexión entre disciplina y biopolítica puede atestiguarse ya en el siglo XVIII, aun cuando las democracias burguesas del siglo XIX llevarán esta mixtura a una de sus expresiones más desarrolladas, con la ayuda de los nacientes saberes sobre las conductas de la sociedad, en particular lo que Foucault llama estadística, que para estos efectos

13 FOUCAULT, Michel. El nacimiento de la biopolítica. Trad. Horacio Pons. Fondo de Cultura Económica. Buenos Aires, Argentina. 2007.

14 FOUCAULT, Michel. El nacimiento de la biopolítica. Op. Cit. p. 19. 
no hay que entender como una disciplina matemática; sino política, es decir, como el estudio de los conjuntos de poblaciones en vistas a su gobierno, o estadística como saber del Estado ${ }^{15}$. Por otra parte, el siglo XX ha sido testigo privilegiado, de esta mixtura entre disciplinas y biopolítica, no sólo en el marco de las democracias burguesas; sino también, a través de los regímenes totalitarios. En esta particular modalidad, se expresa la íntima conexión entre disciplina y biopolítica, al punto que las regulaciones generales de carácter demográfico, se vuelven sistemas de vigilancia racial, altamente disciplinarios, creativos y mortíferos. No se trata de igualar fenómenos distintos como la regulación migratoria y el etnocidio; estos, evidentemente son asuntos muy diferentes. Pero es necesario atestiguar que entre ambos hay una conexión, al menos como lo ha demostrado -y en cierto sentido aún lo demuestra-cierta mentalidad política autoritaria. Ésta es, en términos generales, la primera forma de biopolítica, que tomando la expresión de Foucault, he calificado como una biopolítica de la razón de Estado. Esta primera forma de biopolítica, en cualquier caso, nace y se desarrolla en contacto con las estrategias disciplinarias, y aunque muestra una forma de racionalidad distinta a la racionalidad disciplinaria, de todos modos, ambas tienen una relación estrecha y se desarrollan, al menos en términos temporales, con relativa sincronía. La segunda, en cambio, es lo que podríamos llamar una biopolítica gubernamental, gubernamentalizada, o también neoliberal. Efectivamente entre ellas hay tanto diferencias como relaciones. Lo principal, se juega al nivel de la racionalidad política subyacente.

\footnotetext{
15 "Etimológicamente, la estadística es el conocimiento del Estado, el conocimiento de las fuerzas y los recursos que en un momento dado caracterizan un Estado. Por ejemplo: conocimiento de la población, medida de su cantidad, medida de su mortalidad, de su natalidad, estimación de las diferentes categorías de individuos pertenecientes al Estado con su riqueza respectiva, cálculo de las riquezas virtuales de que dispone el Estado: las minas, los bosques, etc., estimación de las riquezas producidas, estimación de las riquezas circulantes, cálculo de la balanza comercial, medición de los efectos de las tasas y los impuestos; todos estos datos y muchos otros constituirán ahora el contenido esencial del saber del soberano". FOUCAULT, Michel. Seguridad, Territorio, Población. Fondo de Cultura Económica, Buenos Aires, Argentina. 2006. Pág. 320.
} 


\section{Biopolítica y neoliberalismo}

Pues no hay que hacerse ilusiones, el neoliberalismo actual no es en absoluto, como se dice con demasiada frecuencia, el resurgimiento, la recurrencia de viejas formas de economía liberal formuladas en los siglos XVIII y XIX, y que el capitalismo reactiva en nuestros días por una serie de razones que obedecerían tanto a su impotencia, a las crisis que atraviesa, como a cierta cantidad de objetivos políticos o más o menos locales y determinados. ${ }^{16}$

Hasta hace poco, no era algo conocido el hecho de que Foucault hubiera realizado un análisis del poder, o al menos de algunas formas de poder, en las sociedades neoliberales. En efecto, muchas de las formas de recepción del pensamiento de Foucault han enfatizado principalmente el análisis de lo disciplinario y han entendido la biopolítica prácticamente como una proyección de las disciplinas. No obstante, la publicación reciente ${ }^{17}$ de los cursos del Colegio de Francia muestran el particular análisis biopolítico en el escenario neoliberal, principalmente los cursos Seguridad, Territorio, Población, curso que Foucault dictó en el periodo académico 1977-1978, y luego El Nacimiento de la Biopolítica, curso que dictó en el periodo 1978-1979.

En estos cursos, sobre todo en el último, Foucault atestigua las transformaciones del sistema económico y de la racionalidad política subyacente. Tales análisis encuentran una singular aplicabilidad en los eventos actuales, principalmente porque nos encontramos en medio de tal racionalidad política, y ya instalados en la nueva fase de

FOUCAULT, Michel. El nacimiento de la biopolítica. Op. Cit. Pág. 149.

Particularmente Seguridad, Territorio, Población y El Nacimiento de la Biopolítica. a pesar de que como cursos fueron dictados por Foucault en los periodos 1977-1978, y 1978-1979, respectivamente, sólo fueron publicados recientemente, en 2004, por Seuil/Gallimard. La versión castellana data de 2006 y 2007, respectivamente por FCE. Esto explica que en las recepciones más extendidas de Foucault tenga mayor importancia para el caso de la biopolítica y el biopoder, el curso Hay que defender la sociedad, de publicación bastante anterior, 1997. 
transformación del modelo económico, que en tales años, Foucault entreveía. En medio de estas transformaciones políticas y económicas se despliega una nueva forma de poder sobre la vida, que tendrá características comunes con la lógica disciplinaria y con las tecnologías de una biopolítica de la razón de Estado; pero que tendrá también elementos altamente distintivos, por lo cual es necesario considerar ambas lógicas por separado y no confundirlas.

En primer lugar, Foucault ve el neoliberalismo no sólo como una actualización o profundización del liberalismo económico clásico; sino como una transformación profunda, que podríamos entender como una fase completamente distinta del capitalismo contemporáneo, y que a la vez admite modalidades en su interior, incluso con ciertas pugnas. En primer lugar, la idea de mercado, central para el liberalismo clásico, sufre una mutación importante para el neoliberalismo. Mientras, para el liberalismo clásico, el mercado era una realidad principalmente natural, sometida a leyes naturales como la oferta y la demanda, el neoliberalismo considera que el mercado no es una realidad natural, sino un artificio, una realidad económica a crear, administrar y mantener ${ }^{18}$. Por lo tanto para que una industria en particular funcione en una economía de mercado, es necesario crear una serie de condiciones que lo permitan. Tales condiciones no son principalmente económicas, sino estructurales, e incluyen aspectos jurídico-normativos, climáticos, demográficos, entre otros. Dichas condiciones en su conjunto corresponden a lo que los ordoliberales llamaron el marco; que en términos básicos, corresponde al conjunto

\footnotetext{
18 "Y bien, en este punto, los ordoliberales rompen con la tradición del liberalismo de los siglos XVIII y XIX. Y dicen: del principio de la competencia como forma organizadora del mercado no se puede y no se [debe] extraer el laissezfaire. ¿Por qué? Porque, dicen, cuando de la economía de mercado uno deduce el principio del laissez-faire, significa en el fondo que todavía está cautivo de lo que podríamos llamar una 'ingenuidad naturalista', es decir, el hecho de considerar que el mercado, aunque se lo defina por el intercambio o por la competencia, es de todas formas una suerte de dato de la naturaleza, algo que se produce espontáneamente y que el Estado debería respetar en la medida misma en que es un dato de la naturaleza". FOUCAULT, Michel. El nacimiento de la biopolítica. Op. Cit. Pág. 152.
} 
de condiciones que posibilitan el funcionamiento de una industria en particular bajo una economía de mercado, y en términos más generales, el conjunto de condiciones que permiten la extensión de una economía de mercado a una sociedad considerada en su conjunto. Foucault entrega un ejemplo, que conviene revisar, sobre los procesos agrícolas europeos ${ }^{19}$. Me parece conveniente, a la vez, proponer un ejemplo actualizado.

Tomemos un caso que podría aplicarse en Chile. Actualmente existe un sector -más bien informal- de reciclaje de residuos electrónicos, donde existen procesos de recolección llevados a cabo por chatarreros. Su trabajo es fundamentalmente recoger desde la calle, y separar residuos potencialmente reciclables, papeles y cartones de una parte, botellas de vidrio por otra, metales en una tercera, finalmente algún aparato electrónico, que puede incluir material desechable, pero

19 Cfr. FOUCAULT, Michel. El nacimiento de la biopolítica. Op. Cit. Págs 172-174. Se trata de un estudio de Eucken que data de 1952 y versa sobre las condiciones para considerar la agricultura alemana en condiciones de una economía de mercado. El estudio se realiza bajo un supuesto bastante particular en terminos de diagnóstico, es decir, una pregunta básica de diagnóstico podría formularse como la siguiente: Puesto que existen tales condiciones estructurantes para una posible actividad agrícola, entonces ¿qué modelo económico responde a tales condiciones previas de modo que la actividad resulte más eficiente o rentable?; curiosamente el estudio no se genera bajo tal interrogante, sino que por el contrario plantea el problema de un modo como el siguiente: Puesto que sólo es posible, conveniente o deseable una economía de mercado ¿cuáles son las condiciones estructurantes de la actividad agrícola que deben ser modificadas, para que tal modelo económico pueda funcionar? Se trata de una pregunta que revela la dinámica política del asunto. Mientras un diagnóstico mira las condiciones y ofrece una respuesta ad-hoc a tales condiciones, la perspectiva política ya tiene una respuesta, y lo que requiere es hacer el camino contrario, transformar las condiciones, en condiciones ad-hoc, para la respuesta previamente elaborada. No sólo se trata del camino largo, sino de una actitud que podríamos considerar "experimental" más que científica. En tal sentido la conclusión para el ejemplo del estudio de Eucken o para el que aquí ofrezco es similar. "La idea no es: dado el estado de las cosas, ¿cómo encontrar el sistema económico que pueda tener en cuenta los datos básicos propios de la agricultura europea? Sino: visto que el proceso de regulación económico político es y sólo puede ser el mercado, ¿cómo modificar esas bases materiales, culturales, técnicas, jurídicas que están dadas en Europa? ¿Cómo modificar esos datos, cómo modificar ese marco para que aparezca la economía de mercado?" FOUCAULT, Michel. El nacimiento de la biopolítica. Op. Cit. Pág 174. 
también metales preciosos y cobre. Estos chatarreros revenden tales materiales, a quienes pueden procesarlos directamente, o acopiarlos hasta revenderlos a un tercero que tenga las capacidades técnicas de procesarlos y revender el material tratado para ser ocupado como materia prima. Aquí hay un sector productivo, que genera recursos, pero reducidos; no se trata de una industria que funcione en condiciones de una economía de mercado. Repensemos ahora esta industria en condiciones de mercado. En primer lugar, se requeriría un flujo de materiales electrónicos, con una potencial de vida útil relativamente calculable y por tanto administrable. En segundo lugar, se requeriría una división de los subprocesos que actúan sobre el proceso general; por tanto, una proliferación de fórmulas de recolección, que cumplan con ciertas condiciones como prácticas especializadas, condiciones de transportes, seguros de responsabilidad, laborales, cotizaciones, etc. De este modo, el subproceso de recolección quedaría relativamente preparado; pero requeriría a su vez, un segundo subproceso organizado de acopio de materiales y disposición para su tratamiento, y a la vez métodos seguros de disposición final del material resultante no reciclable. Finalmente un conjunto de empresas con la tecnología necesaria para reducir los componentes a materias primas y ser reutilizados por otras empresas productoras. La organización de estos subprocesos implica una pirámide de gestión, donde actúan una enorme cantidad de agentes recolectores, algunos menos acopiadores, y finalmente unos pocos agentes recicladores. Del mismo modo, la curva de inversión es inversamente proporcional, mientras la inversión de los recolectores es baja y se encuentra ampliamente distribuida, la inversión es mayor en los acopiadores y también menos distribuida, hasta llegar a una gran inversión en los agentes recicladores, por las necesidades tecnológicas que requieren, y a la vez altamente concentrada en un grupo pequeño de agentes. Evidentemente tal organización, requiere la interacción con otros sectores productivos principalmente el de transporte, y una relación estrecha con el sector financiero; por los flujos de inversiónendeudamiento que su instalación requiere. Del mismo modo, se requiere un mercado de trabajo y un marco regulativo ad-hoc. Lo que quiero decir, con esto, en principio, no es que la transformación 
anterior sea inconveniente o conveniente, sino que para que algo así se lleve a cabo requiere una serie de intervenciones. Ninguna de estas condiciones se genera espontáneamente.

Contrariamente a pensar el mercado de manera natural, para que una industria en específico, y una sociedad en su conjunto funcionen en una economía de mercado se precisan una serie de intervenciones del Estado. En primer lugar, la legislación que incentiva el surgimiento de la necesidad productiva, en el caso del ejemplo que he dado, una legislación que o incentive el reciclaje o lo prescriba de manera obligatoria. A la vez que una legislación que busque condiciones de seguridad para tal actividad. Lo que impacta en el mercado de seguros, pues incentiva la creación de seguros de transporte, de responsabilidad, de salud o laborales. Al mismo tiempo, se necesitan crear las condiciones financieras que permitan un sistema crediticio, para solventar la curva de inversiones en las diversas fases de la pirámide, desde el crédito al microempresario recolector hasta el gran inversor de las plantas de reciclaje, con las implicancias tecnológicas de estas mismas. De este modo, la inserción de una industria particular en una economía de mercado requiere una serie de condiciones estructurales que no están dadas de manera natural, sino que es preciso planificar, construir y mantener. De este modo, el neoliberalismo no aparece -a diferencia de muchas opiniones comunes- como un modelo que rehúse la intervención del Estado; por el contrario es un modelo que requiere mucha intervención política. Ahora bien, se trata de intervenciones estructurales que operan sobre este "marco". La intervención que el neoliberalismo rechaza es la intervención que considera "económica", vale decir, la fijación de precios, del mercado monetario, de las tasas de producción, de los salarios u otras similares ${ }^{20}$. De este modo, la

\footnotetext{
20 "¿Será preciso entonces actuar sobre qué? No sobre los precios, no sobre tal o cual sector poco rentable para asegurar su sostén: todas esas intervenciones son malas. ¿Sobre qué actuarán las buenas intervenciones? Y bien, sobre el marco. Es decir, primero, sobre la población... También habrá que intervenir en el plano de las técnicas... En tercer lugar, modificar también el régimen jurídico... Cuarto, modificar, en la medida de lo posible, la distribución de los suelos y la extensión, la naturaleza y la explotación de las tierras disponibles. Para terminar,
} 
implementación del mercado no rechaza la intervención del marco, incluso, la requiere. Nunca una economía de mercado llega a instalarse, si no es a través de una fuerte intervención política y en ningún caso, por una evolución natural21 ${ }^{21}$ Esta forma de pensar propia del neoliberalismo, en general resulta altamente diversa a la concepción de un mercado natural dado, que evoluciona a partir de leyes naturales hacia un destino igualmente natural, que en cierto sentido se identifica mucho más con el liberalismo clásico. La concepción neoliberal, por el contrario, es altamente política, considera el mercado una realidad política que es necesario crear, y para ello intervenir. Se genera un efecto de acercamiento entre política y economía. A la mentalidad neoliberal no le molesta la esfera política; por el contrario, la política es necesaria para el mercado, pues desde la esfera política se generan las condiciones para el funcionamiento de los diversos mercados. $Y$ esto es una necesidad permanente. Por una parte se requieren grandes intervenciones políticas iniciales ${ }^{22}$; pero también, la expansión del

y en última instancia, es preciso poder intervenir sobre el clima". FOUCAULT, Michel. El nacimiento de la biopolítica. Op. Cit. Pág. 173.

21 "La competencia como lógica económica esencial sólo aparecerá y producirá sus efectos de acuerdo con una cantidad de condiciones que habrán sido cuidadosa y artificialmente establecidas". FOUCAULT, Michel. El nacimiento de la biopolítica. Op. Cit. Pág. 153.

22 A propósito de esto, si bien nos distrae del objeto principal que estamos tratando, es necesario detenerse en esta necesidad de grandes intervenciones políticas iniciales que el neoliberalismo promueve y las economías de mercado requieren. Este conjunto de intervenciones que el propio Friedman consideraba como una estrategia de shock. Según la famosa expresión, muchas veces repetida por el propio Friedman, y acuñada en el encuentro personal entre Friedman y Pinochet "I believe that the experience of Germany and Japan after World War II, of Brazil more recently, of the post-war readjustment in the U.S. when government spending was slashed drastically an rapidly, all argue for shock treatment". FRIEDMAN, Milton. FRIEDMAN, Rose. TWO LUCKY PEOPLE: MEMOIRS. University of Chicago Press. Chicago-London 1999. Pág. 592. Una traducción castellana de esta carta, junto a un testimonio de José Piñera, están disponibles en http://www.elcato.org/milton-friedman-ysus-recomendaciones-chile. Foucault analiza básicamente las experiencias alemana y norteamericana, en ambas ve un elemento común de la mayor importancia, y que llama "el campo de adversidad necesaria". Se refiere con esto, a que la implementación inicial de políticas neoliberales implica una intervención política tan grande, tan estructural, que requiere legitimarse sobre un campo previo de adversidad, una situación de crisis, ante la cual 
mercado a nuevos sectores productivos, requiere que permanentemente se estén creando marcos de funcionamiento para estos nuevos ámbitos emergentes.

Esta primera característica de la relación entre economía y política que Foucault asigna principalmente al ordoliberalismo alemán, se ve profundizada en lo que llama el anarcoliberalismo, de origen más bien norteamericano. En este caso, no sólo existe relación entre política y mercado; sino que se genera una expansión de la racionalidad de mercado, a nuevos ámbitos que no pertenecen necesariamente al plano económico, como la familia, la educación, y principalmente la

se ofrezca como respuesta y que le allane el camino ya de legitimación, ya de consenso, depende del caso. Tal campo de adversidad lo constituye en el caso de Alemania, principalmente el régimen nazi y la necesidad de reconstrucción de postguerra. En el caso norteamericano, la crisis económica derivada de políticas keynesianas, y particularmente la crisis de carácter más político, en relación con el New Deal. En ambos casos, la solución neoliberal se presenta como respuesta a una situación de crisis, logra consentimiento para emprender fuertes transformaciones, a partir de la adversidad previa. Esto también sucede en el caso chileno, que además de reaccionar frente a la situación de crisis inflacionaria, tiene la particularidad de llevarse a cabo como política oficial de la dictadura. De este modo las grandes transformaciones político-económicas, que difícilmente podrían llevarse a cabo sin una gran agitación social y con el rechazo de sectores sociales importantes, se ven legitimadas como solución drástica a una crisis, o directamente acalladas en el caso de la dictadura. En cierto sentido, esta característica es común a los dos grandes procesos de transformación neoliberal de la actualidad. Me refiero al paquete de reformas de la Unión Europea, que difícilmente serían aceptadas sino como "solución drástica a la crisis", y aun así, crean resistencia de movimientos sociales diversos, aunque finalmente se encaminan a la instalación de prácticas cada vez más neoliberales. Y, por otro lado, a lo que se ha llamado "la revolución del siglo XXI", es decir, a los procesos políticos de los países del Medio Oriente, que se libran de un campo de adversidad como las dictaduras, para incorporarse a las democracias liberales, con su consecuente apertura de mercados. A la implementación inicial de políticas liberales se le ha definido, en alguna ocasión, como revolución, justamente por la envergadura de intervenciones que requiere. Ahora bien, se trata de una revolución que en ningún caso es silenciosa, sino legitimada a partir de un campo de adversidad previa, es decir, que provoca el silencio social, por presentarse como remedio a una situación insostenible previa, o porque directamente acalla, silencia, como en el caso de la dictadura chilena. 
política ${ }^{23}$. De tal modo que surge el Estado gubernamentalizado ${ }^{24}$, es decir, un estado que paradójicamente ya no funciona bajo la razón de Estado, sino bajo una razón que Foucault llama gubernamental. La gubernamentalidad implica aquí un tipo particular de racionalidad política, altamente biopolítica. Se trata de un Estado que interviene en la economía, no para regular el mercado, sino para producirlo y mantenerlo. Esta idea de gubernamentalidad tiene altas complejidades y conviene dedicarle algo más de tiempo. En Seguridad, Territorio, Población, Foucault nos ofrece un pasaje fundamental para entenderla.

Por "gubernamentalidad" (...) entiendo el conjunto constituido por las instituciones, los procedimientos, análisis y reflexiones, los cálculos y las prácticas que permiten ejercer esta forma tan específica, tan compleja, de poder, que tiene como meta principal la población; como forma primordial de saber, la economía política; como instrumento técnico esencial, los dispositivos de seguridad. ${ }^{25}$

23 "...el neoliberalismo norteamericano se presenta, sin duda, con un carácter radical mucho más riguroso o mucho más completo y exhaustivo. En efecto, su ambición constante es generalizar la forma económica del mercado. Se trata de generalizarla en la totalidad del cuerpo social y hasta en el sistema social completo que, por lo común, no pasa ni es sancionado por intercambios monetarios. Esta generalización en cierto modo absoluta, esta generalización ilimitada de la forma del mercado, entraña una serie de consecuencias o implica una serie de aspectos (...) la generalización de la forma económica del mercado, más allá de los intercambios monetarios, funciona en el neoliberalismo norteamericano como principio de inteligibilidad, principio de desciframiento de las relaciones sociales y los comportamientos individuales". FOUCAULT, Michel. El nacimiento de la biopolítica. Op. Cit. Pág. 280.

24 "En otras palabras en lugar de aceptar una libertad de mercado definida por el Estado y mantenida de algún modo bajo vigilancia estatal -lo cual era, en cierta forma, la fórmula inicial del liberalismo: establezcamos un espacio de libertad económica, circunscribámoslo y dejémoslo circunscribir por un Estado que ha de vigilarlo-, pues bien, dicen los ordoliberales, es necesario invertir por completo la fórmula y proponerse la libertad de mercado como principio organizador y regulador del Estado, desde el comienzo de su existencia y hasta la última forma de sus intervenciones. Para decirlo de otra manera, un Estado bajo la vigilancia del mercado más que un mercado bajo la vigilancia del Estado". FOUCAULT, Michel. El nacimiento de la biopolítica. Op. Cit. Pág. 149.

25 FOUCAULT, Michel. Seguridad, Territorio, Población. Op. Cit. Pág. 136. 
Lo primero que conviene apuntar, es que la gubernamentalidad no es un fenómeno que le suceda al Estado, sino que podríamos considerarlo más bien exógeno. Es decir, se trata de una forma de gobierno y ejercicio del poder, pero en el que están implicados una serie de instituciones, prácticas, procedimientos y saberes. El Estado entre otras instituciones. Así como la sociedad disciplinaria tendía a una cierta estatalización del conjunto social, aquí el movimiento es inverso, se tiende más bien a una gubernamentalización del Estado, pero también del resto de las instituciones. La meta de esta forma de poder y su racionalidad política, no son los individuos, como en el caso de la sociedad disciplinaria, sino las poblaciones en su conjunto. Es decir, regulaciones generales, donde ningún sujeto en particular es obligado a algo en particular, sino que se generan procesos sobre la población, y los sujetos quedan insertos en ellos. Al mismo tiempo, así como la sociedad disciplinaria, tenía una relación con los saberes siquiátricos, criminalísticos, educativos, y en general con las ciencias humanas, esta nueva forma de poder tiene una relación principal con la economía política. Es decir, así como las ciencias humanas desempeñaban un papel al fijar cierto patrón de normalidad para los individuos, en la actualidad la economía política juega el papel principal al fijar las modalidades de comportamiento general de la población, que ya no serán ni criminalizantes, ni moralizadoras, sino sobre todo económicas. De este modo, las formas en las que se ejerce el poder serán fundamentalmente las regulaciones económicas de la población. Aunque aquí, hay que poner un signo de atención sobre lo que significa regulación, pues ella implica no sólo las prohibiciones y coacciones, sino tanto las prohibiciones y coacciones, como las libertades. La lógica de la prohibición, perteneciente a la ley, y la de la obligación, correspondiente a las disciplinas, se ve complementada con la regulación de las poblaciones, que ya no prescribe prohibiciones u obligaciones, sino que administra las libertades. Respecto de lo anterior resultan muy gráficos los argumentos que Foucault proporciona para mantener el adjetivo "liberal".

Si empleo el término "liberal" es ante todo porque la práctica gubernamental que comienza a establecerse no 
se conforma con respetar tal o cual libertad, garantizar tal o cual libertad. Más profundamente, es consumidora de libertad. Y lo es en la medida en que sólo puede funcionar si hay efectivamente una serie de libertades: libertad de mercado, libertad del vendedor y el comprador, libre ejercicio del derecho de propiedad, libertad de discusión, eventualmente libertad de expresión, etc. Por lo tanto, la nueva razón gubernamental tiene necesidad de libertad, el nuevo arte gubernamental consume libertad. Consume libertad: es decir que está obligado a producirla. Está obligado a producirla y está obligado a organizarla. ${ }^{26}$

Finalmente, el instrumento técnico -la tecnología- por el cual se llevan a cabo estos procesos, ya no será el de los dispositivos disciplinarios y las formas del encierro, sino lo que Foucault llama dispositivos de seguridad. Para presentarlos, Foucault los opone por contraste a los procedimientos legales y los dispositivos disciplinarios ${ }^{27}$. Se trata, en los dispositivos de seguridad, de calcular lo deseable. Si la ley actuaba por prohibición, y el dispositivo disciplinario por obligación, los dispositivos de seguridad buscan modular un rango de lo conveniente y lo tolerable. Es decir, establecen un rango al interior del cual es aceptable lo anómalo y aleatorio, y existe un nivel de incorporación de aquello no deseable ni conveniente, pero tolerable en una medida que no altera el rango general de regulación. De este modo, los dispositivos de seguridad se instalan en una tensión entre la administración de las libertades y el saber regulativo. Dicho de otro modo, si la función de la ley consistía en prohibir, y la de las disciplinas en obligar, el dispositivo de seguridad juega con el permitir.

\footnotetext{
26 FOUCAULT, Michel. El nacimiento de la biopolítica. Op. Cit. Pág. 84.

27 "En otras palabras, la ley prohíbe, la disciplina prescribe y la seguridad, sin prohibir ni prescribir, y aunque eventualmente se den algunos instrumentos vinculados con la interdicción y la prescripción, tiene la función esencial de responder a una realidad de tal manera que la respuesta la anule: la anule, la limite, la frene o la regule. Esta regulación en el elemento de la realidad es, creo, lo fundamental en los dispositivos de la seguridad". FOUCAULT. Michel. Seguridad, Territorio, Población. Op. Cit. p. 69.
} 
De este modo, la extensión de la racionalidad del mercado, se traduce en gubernamentalidad, y para lo que nos interesa -que son los procesos de poder sobre los sujetos-, genera un mercado vital a partir de los sistemas de capitalización individual. La razón de Estado veía procesos colectivos y necesidades de la sociedad en conjunto, y por lo tanto, creaba vastos sistemas estatales de salud, de educación o de pensiones; por el contrario, la racionalidad gubernamental neoliberal, ve necesidades individuales y ofertas de servicios diferenciados, y por lo tanto, un mercado vital. Dicho de otro modo, hace funcionar la vida de los sujetos en cuanto mercado, de tal modo que cambia la fórmula del sistema estatal a la capitalización individual, las necesidades de los individuos se transforman en un objeto económico, que como cualquier otro, debe ser entendido bajo una racionalidad de mercado, y para que funcione como tal, deben ser creadas las condiciones de tal mercado, a través de los sistemas de capitalización individual.

Nuevamente la experiencia chilena resulta altamente ilustrativa. La transformación de un sistema público educacional unificado en una red de servicios educacionales diferenciados y privados es la primera gran etapa del mercado vital. Los individuos deben hacer su primera gran inversión en educación, escogiendo el servicio educacional que les parezca más adecuado y costeando la entrega de estos servicios. La racionalidad de mercado se instala así en el seno de la familia; pues son los padres quienes toman estas decisiones y costean estos servicios en nombre de sus hijos, en el caso chileno con un nivel de subvención que el Estado entrega vía outsourcing. Sin embargo, esta condición hace que la cantidad de hijos o la separación de tiempo entre el nacimiento de uno y otro, se transformen en decisiones económicas que la familia debe afrontar. Para que esto funcione, requiere una serie de condiciones. La primera de ellas es la desigualdad. Los servicios educacionales deben ser percibidos por sus potenciales clientes, en un abanico de desigualdad; pues si existe una relativa igualdad entre unos servicios y otros, nada hace que un potencial cliente elija uno y no otro. Por lo tanto, se requiere una distribución desigualitaria, que pasa fundamentalmente por dos ejes. Primero, una percepción 
de calidad, y segundo, una percepción de futuro. La percepción de calidad se logra fácilmente a través de la estandarización de instrumentos técnicos que fijan rangos de calidad. Funciona de este modo la estandarización de rangos, de manera similar a como funcionaban los procesos de normalización disciplinarios. En Chile estos instrumentos técnicos son fácilmente reconocibles y apuntan en dos direcciones. La selección universitaria, PSU, por una parte, y la evaluación de procesos, a través de SIMCE. Lo primero entrega la promesa de futuro, que es el producto básico que consumen los clientes en educación; lo segundo permite estratificar los servicios educacionales en una gama de unidades más aceptables o menos aceptables según el rango de calidad. De tal modo, habrá unidades en rojo, en amarillo, o en verde, según la tristemente célebre metáfora del semáforo. En definitiva, una percepción de marca y calidad, aplicable a los distintos servicios educacionales, y que logra la ecuación básica precio-calidad común a la lógica general de mercado. Es decir, que para obtener servicios de calidad, comúnmente, habrá que pagar más caro, como es lógico al comprar cualquier producto. Se trata de un mercado educacional, que evidentemente no se logra espontáneamente. En primer lugar, se requiere la descentralización del sistema educacional, y de hecho dejar de pensar en un sistema educacional unitario, y pensar en servicios diferenciados. Esto requiere un fundamento jurídico, que consagre el derecho a la diversidad de servicios educacionales, por una parte; en segundo lugar, que redistribuya las tareas del Estado, desde la obligación de impartir y proveer educación, al modelo del outsourcing, vale decir, externalizar, pagar por servicios externos, y controlar los rangos de calidad de tales servicios externos. Para lograr esto, el Estado debe necesariamente librarse jurídicamente de la obligación de educar, de lo contrario incumple al menos una de sus tareas. Es decir, requiere reestructuraciones legales de diverso tipo: leyes de educación, reformas constitucionales, proyectos de ley, acuerdos políticos. En ningún caso, la transformación del sistema educacional en mercado educacional es una evolución natural. Del mismo modo, este mercado tampoco funciona, sino a través de una concepción técnica de calidad, es decir, sin el desarrollo de una serie de saberes especializados, 
administrativos, de capacitación, entre otros. Tampoco funciona sin una red de proveedores de servicios educacionales; por lo tanto, no funciona si se le extrae la noción de lucro. Pues, un proveedor de servicios educacionales es una empresa y por definición una empresa tiene como objetivo rentabilizar. En fin, un mercado educacional no funciona sin una serie de condiciones que lo hacen posible y que no son condiciones espontáneas ni sólo económicas, sino condiciones estructurales o de marco.

Como es posible apreciar, en todo caso, el mercado educacional constituye en sí mismo sólo un mercado, y si bien cubre gran parte, en años, de la vida de los individuos, no es en sí mismo el mercado vital. Para que un mercado vital llegue a constituirse, se requiere que el resto de las condiciones de subsistencia de los sujetos funcione en una economía de mercado. Es decir, requiere que el mercado educacional se vincule al mercado del trabajo, como efectivamente ocurre, pues el hecho de que una mejor capacitación redunda, comúnmente, en una mejor posición en el mercado del trabajo, no es una falsedad, en el modelo económico actual. Del mismo modo, el mercado del trabajo debe vincularse al mercado de pensiones, los sistemas sanitarios, y los mercados crediticios. En resumen, se constituye un mercado vital, en el que los individuos ejercen como clientes respecto de ciertos productos y que puede entenderse a partir de la idea de "capital humano". La teoría del capital humano logra transformar radicalmente la idea de trabajo. La relación trabajo-salario, que constituye la concepción clásica de la economía respecto del trabajo, se ve transformada por la idea de rentabilidad. Los sujetos ya no venden su fuerza de trabajo por un salario, sino que rentabilizan un capital. Dicho de otro modo, ya no tienen solamente fuerza de trabajo que ofrecer a cambio de un salario, sino una serie de otros elementos que constituyen un capital propio, ni monetario ni de infraestructura, sino humano: la suma de sus capacidades, los conocimientos adquiridos, las experiencias y relaciones, el manejo adecuado de uno o varios idiomas, la imagen personal, la proyección de status o de éxito económico. Se trata de un hombre-empresa que invierte en su propio capital -educación, 
relaciones sociales, imagen-, y genera rentabilidad de tal capital ${ }^{28}$. Por tal razón, una más prolongada, más prestigiosa o mejor educación, relaciones sociales y familiares convenientes o influyentes, una imagen personal y profesional adecuada o socialmente valorada, redundan, comúnmente, en una rentabilidad mayor a nivel económico. Se trata de un hombre-empresa, que interactúa con otras empresas: otros hombres-empresa, la familia-empresa, la escuela-empresa, la universidad-empresa, la salud empresarial. "Es necesario que la vida misma del individuo -incluida la relación, por ejemplo, con su propiedad privada, su familia, su pareja, la relación con sus seguros, su jubilación- lo convierta en una suerte de empresa permanente y múltiple ${ }^{\prime 29}$. Esta lógica de inversión sobre sí mismo, y de rentabilidad personal, requiere necesariamente una lógica de desigualdad. Efectivamente, sólo a través de la desigualdad es posible que un individuo, al que no se le obliga a competir ni a consumir, elija de manera permanente participar en el mercado vital. La coacción cambia profundamente desde la sociedad disciplinaria, que obligaba por medio del encierro, del castigo físico o de la ortopedia. En el mercado vital, la coacción es fundamentalmente económica. A ningún individuo se le obliga a participar de manera directa o violenta en el juego económico. No es necesario, pues quien no participa de tal mercado, quien no invierte en su propio capital, recibirá tarde o temprano las sanciones económicas derivadas de su propio comportamiento económico. Es decir, se transformará en una empresa no viable, en quiebra, pasará a formar parte de las masas desfavorecidas. La desigualdad es el agente políti-

\footnotetext{
28 "Desde el punto de vista del trabajador, el salario no es el precio de venta de su fuerza de trabajo, es un ingreso. $Y$ en este punto, entonces, los neoliberales norteamericanos se refieren a la vieja definición, de comienzos del siglo XX, de Irving Fisher que decía: ¿qué es un ingreso? ¿Cómo se lo puede definir? Un ingreso es sencillamente el producto o rendimiento de un capital. Y a la inversa, se denominará "capital" a todo lo que pueda ser, de una manera u otra, fuente de ingresos futuros. Por consiguiente, sobre esa base, si se admite que el salario es un ingreso, el salario es por lo tanto la renta de un capital. Ahora bien, ¿qué es el capital cuya renta es el salario? Bueno, es el conjunto de los factores físicos, psicológicos, que otorgan a alguien la capacidad de ganar tal o cual salario". FOUCAULT, Michel. El nacimiento de la biopolítica. Op. Cit. p. 262.

29 FOUCAULT, Michel. El nacimiento de la biopolítica. Op. Cit. p. 277.
} 
co que estimula en forma permanente la participación de los sujetos en el mercado vital. Por tal razón es funcional y necesaria para que el mercado vital funcione, sin la desigualdad no existe el juego de la competencia ${ }^{30}$. Foucault ve en este juego de la desigualdad una de las transformaciones claves del neoliberalismo respecto al liberalismo clásico mercantilista. Pues el liberalismo clásico, veía en la equivalencia la base del intercambio mercantil. Sólo un intercambio entre iguales aseguraba el funcionamiento del mercado. La desigualdad como motor económico es una innovación neoliberal, y una innovación que el mercado vital requiere mantener para su funcionamiento en vistas a la competencia ${ }^{31}$.

De este modo, queda constituido un mercado vital que traza una línea de comportamientos socialmente adecuados o legítimos que van desde la infancia a la edad adulta, comportamientos fundamentalmente constituidos por procesos económicos y que instalan un proyecto de vida, bastante particular, que siguiendo la expresión de Foucault he denominado aquí como el de hombre-empresa ${ }^{32}$.

A los procesos educacionales concebidos como preparación individual para el mercado del trabajo y financiados a través de una serie de instrumentos crediticios, le siguen la incorporación al mercado del trabajo,

30 "La competencia como lógica económica esencial sólo aparecerá y producirá sus efectos de acuerdo con una cantidad de condiciones que habrán sido cuidadosa y artificialmente establecidas". FOUCAULT, Michel. El nacimiento de la biopolítica. Op. Cit. Pág. 153.

31 "Ahora bien, para los neoliberales lo esencial del mercado no está en el intercambio, esa especie de situación primitiva y ficticia imaginada por los economistas liberales del siglo XVIII. Está en otra parte (...) lo esencial del mercado es la competencia: entonces ya no es la equivalencia, sino, al contrario, la desigualdad". FOUCAULT, Michel. El nacimiento de la biopolítica. Op. Cit. Pág. 151.

32 "En el neoliberalismo -que no lo oculta, lo proclama- también vamos a encontrar una teoría del homo œeconomicus, pero en él este no es en absoluto un socio del intercambio. El homo ceconomicus es un empresario, y un empresario de sí mismo. Y esto es tan cierto que, en la práctica, va a ser el objetivo de todos los análisis que hacen los neoliberales: sustituir en todo momento el homo œeconomicus socio del intercambio por un homo œconomicus empresario de sí mismo, que es su propio capital, su propio productor, la fuente de [sus] ingresos". FOUCAULT, Michel. El nacimiento de la biopolítica. Op. Cit. Págs. 264-265. 
y con ella al mercado de los seguros de salud y previsionales, en vista a satisfacer la cobertura sanitaria y de pensiones, que se complementan con los instrumentos crediticios con objeto hipotecario, que por lo demás aseguran una buena cantidad de años de endeudamiento. En esta línea vital de mercado, la herramienta del endeudamiento aparece como la herramienta principal de ortopedia social; una dosis de endeudamiento sostenible, pero permanente, asegura que ningún individuo se sustraiga completamente del juego económico. De este modo, la inversión en la propia educación, financiada en plazos, se suma al crédito hipotecario, pagado en diversas tasas de interés de largo plazo, y la permanente cotización previsional durante todo el periodo de vida laboral en vistas a una jubilación futura, configuran una situación de endeudamiento permanente. Como proponía Deleuze, "El hombre ya no está encerrado sino endeudado ${ }^{1 / 33}$. El mercado vital, que opera bajo la interfaz del hombre-empresa, se presenta así como proyecto vital, el del hombre-empresario-de-sí-mismo. Sobre los procesos de construcción de sí mismo que cada sujeto lleva a cabo, sobre las elecciones que hace para su propia vida, y sobre el proyecto de sí mismo que elige para llevar a cabo a lo largo de su vida, pesa este proyecto previo que actúa moldeando las decisiones, administrando la libertad y el deseo.

La biopolítica, el poder sobre la vida, se expresa entonces en el contexto del neoliberalismo, a través de modalidades fundamentalmente económicas que tienden a su invisibilización. En efecto, ya no se trata del poder hosco y brutal, de los dispositivos disciplinarios, altamente reconocible y fácilmente denunciable, sino de una forma de poder que pareciera menos autoritario, aunque más expansivo y altamente eficaz, en la medida que deja capturada la vida de los sujetos en una interfaz previa, muy difícil de romper.

Lo que aparece en el horizonte de un análisis como éste no es de ningún modo el ideal o el proyecto de una sociedad

33 DELEUZE, Gilles. Post-scriptum sobre las sociedades de control. En DELEUZE, Gilles. Conversaciones. Trad. José Luis Pardo. Pretextos. Valencia. 1996. Pág. 284. 
exhaustivamente disciplinaria en la que la red legal que aprisiona a los individuos sea relevada y prolongada desde adentro por mecanismos, digamos, normativos. No es tampoco una sociedad en la que se exija el mecanismo de la normalización general y la exclusión de lo no normalizable. En el horizonte de ese análisis tenemos, por el contrario, la imagen, la idea o el tema-programa de una sociedad en la que haya una optimización de los sistemas de diferencia, en la que se deje el campo libre a los procesos oscilatorios, en la que se conceda tolerancia a los individuos y las prácticas minoritarias, en la que haya una acción no sobre los participantes del juego, sino sobre las reglas del juego, $y$, para terminar, en la que haya una intervención que no sea del tipo de la sujeción interna de los individuos, sino de tipo ambiental. ${ }^{34}$

Desde esta perspectiva, el mercado vital, y una sociedad de mercado en su conjunto requieren formas de libertad. Formas administradas, reguladas, con rangos de libertad que incluyan ciertas formas de diferencia o incluso de resistencia. Pues sin cierto ejercicio de libertades el mercado no funciona. Sin embargo, al mismo tiempo se transforma en un potente modelador de libertades. Tiene que vérselas, de este modo, con la paradoja de la libertad: el neoliberalismo requiere libertades y las consume en forma permanente. La diferencia sistematizada, la resistencia administrada, la protesta autorizada, la tolerancia a las minorías, son parte de este juego de las libertades. En efecto, el mercado vital no funciona como funciona un régimen autoritario, ni como una cárcel, ni como un campo de concentración; por el contrario, funciona de manera más sutil y eficaz. En este juego de las libertades, los sujetos pueden elegir su imagen personal, el barrio en el que quieren vivir, el colegio de sus hijos, la aseguradora de salud que prefieran, el modelo de auto que gusten, el candidato que les parezca conveniente. Pero

34 FOUCAULT, Michel. El nacimiento de la biopolítica. Op. Cit. pp. 302303. 
todas estas elecciones se dan al interior de un proyecto de construcción de sí mismo que ya está subordinado al modelo del hombre-empresa. El neoliberalismo ejerce el biopoder no desde la imposición individual a los sujetos, ni a través del castigo o la disciplina; sino que genera un marco vital a partir de regulaciones generales y tecnologías económicas que nunca obligan a los sujetos a una decisión o acción particular. Es posible incluso que un sujeto no elija, desobedezca, resista por mucho tiempo, sin que se le discipline o castigue; pues finalmente las consecuencias económicas de su comportamiento inadecuado, le harán o retomar comportamientos conformes o integrarse a la masa social desfavorecida que sirve de referente básico a los demás, para estimular la inversión sobre sí mismo y evitar el detrimento social y económico. Ni los lugares de encierro, ni el viejo modelo del panóptico se requieren ya, resultan tan salvajes como anticuados. Siguiendo la imagen propuesta por Esposito, el biopoder ha descubierto las ventajas, la sofisticación y la elegancia de las funciones inmunitarias. Al igual que el procedimiento de la vacunación, lo más eficiente para combatir lo peligroso es aceptar pequeñas dosis de ello, inocular una cierta dosis de resistencia, diferencia y protesta, resulta altamente eficaz para inmunizar al organismo en su conjunto.

Lo que he presentado hasta aquí obedece, por decirlo en términos gruesos, a la descripción de una "lógica pura". Vale decir, de lo que Foucault calificaba en la cita anterior como "la imagen, la idea o el tema-programa de una sociedad". En cierto sentido, en un país como Chile, quienes hemos atestiguado la formación de este proceso, y hemos además padecido los sistemas de capitalización individual y endeudamiento, nos resulta una lógica relativamente fácil de entender. En cierto sentido, hemos sido y somos, hombre-empresa. Ahora bien, es interesante que Foucault observe esta lógica como un proceso en instalación, y además como un programa. Es decir, se trata de un diagnóstico, no tanto de un hecho acaecido de una vez y para siempre, sino de una forma emergente de poder que en efecto está en proceso de instalación, a partir de estrategias muy diversas, en sociedades distintas. De este modo, es necesario pensar tal lógica 
de poder, no como una lógica pura, sino como una línea de fuerza, que se superpone sobre otras líneas de fuerza, tanto antagónicas, como subyacentes. Respecto a las líneas de fuerza subyacentes, es necesario pensar que el modelo biopolítico neoliberal no anula ni los procedimientos legales, ni los disciplinarios. Más bien el trinomio leydisciplina-regulación constituye un montaje de lógicas que conviven. De este modo, me parece interesante pensar el biopoder, bajo la idea de diagrama, que Deleuze toma de Foucault para desarrollarla.

\section{Diagrama}

El marco de comprensión del análisis de Foucault sobre el biopoder, remite a un análisis más amplio respecto de las formas del poder y su relación con los saberes y con las formas de producción de subjetividad. Este es el marco que, de hecho, permite comprender el análisis de las disposiciones legales en las formas de la soberanía; después, el análisis de los dispositivos de la sociedad disciplinaria; y finalmente, las formas de la biopolítica, tanto en lo que refiere a una biopolítica de la razón de Estado, como a una biopolítica gubernamentalizada. En este sentido, si bien Foucault propone un rumbo que podemos indicar cronológicamente, y tal rumbo implica desplazamientos en una dirección reconocible, es decir, de la soberanía a las disciplinas y de las disciplinas a la biopolítica, tales formas no funcionan como lógicas puras o abstractas; sino que por mecanismos de superposición. Por tal razón conviene pensar los mecanismos del biopoder, no como una clausura definitiva de los mecanismos del poder soberano, o del régimen legal, sino como una superposición de elementos.

... es preciso comprender las cosas no como el reemplazo de una sociedad de soberanía por una sociedad de disciplina, y luego de una sociedad de disciplina por una sociedad, digamos, de gobierno. De hecho, estamos ante un triángulo: soberanía, disciplina y gestión gubernamental, cuyo blanco principal es la población y cuyos mecanismos esenciales son los dispositivos de seguridad... A mi entender, es necesario 
señalar que estos tres movimientos: gobierno, población y economía política, constituyen desde el siglo XVIII una serie sólida que, sin duda, ni siquiera hoy está disociada. ${ }^{35}$

Para el tema que estamos analizando -que es el modelo del hombreempresa como dispositivo de seguridad o interfaz biopolítica-, este asunto es de la mayor importancia. Tal modelo no funciona en una lógica abstracta, sino que se monta, en cuanto dispositivo biopolítico gubernamental, sobre otros dispositivos que le sirven de andamiaje. Por tal razón, el homo œeconomicus neoliberal -el modelo del hombre empresa-constituye la elaboración más novedosa del biopoder, y a la vez marca el rumbo general hacia el que se dirige el poder sobre la vida. No obstante, no se trata del único dispositivo en funcionamiento. Este dispositivo se monta -en más de un sentido requiere hacerlo- sobre los dispositivos disciplinarios previos, que perviven y complementan la acción del dispositivo gubernamental. Estos dispositivos disciplinarios ya no funcionan como dispositivo principal; sino como mecanismos de apoyo. En tal sentido, es importante recalcar que el modelo del hombre-empresa marca el rumbo principal de los mecanismos de control, y a la vez debe convivir, en una relación de pugna y continuidad, con mecanismos disciplinarios. Me parece que esto es lo que ha comprendido Deleuze cuando plantea que las sociedades disciplinarias son lo que estamos dejando de $\operatorname{ser}^{36}$, al mismo tiempo que muestra cómo sus mecanismos perviven, y en ningún caso se han agotado ${ }^{37}$. Se trata de comprender dos cosas a la vez: a) que hay una tendencia

35 FOUCAULT, Michel. Seguridad, Territorio, Población. Op. Cit. Pág. 135.

36 "Las sociedades disciplinarias son nuestro pasado inmediato, lo que estamos dejando de ser". DELEUZE, Gilles. Post-scriptum sobre las sociedades de control. En DELEUZE, Gilles. Conversaciones. Trad. José Luis Pardo. Pretextos. Valencia. 1996. Pág. 278.

37 "Foucault nunca pensó, y así lo dijo con toda claridad, que las sociedades disciplinarias fueran eternas. Todo lo contrario: pensaba obviamente que estamos entrando en un nuevo tipo de sociedad. Claro que quedan toda clase de residuos de las sociedades disciplinarias, y así será durante años y años, pero ya sabemos que estamos ingresando en otro tipo de sociedad". DELEUZE, Gilles. ¿Qué es un acto de creación? En DELEUZE, Gilles. Dos regímenes de locos. Trad. José Luis Pardo. Pre-textos. Valencia. 2008. Pág. 287. 
de transformación de los mecanismos de poder, y que esa tendencia tiene una direccionalidad, que tiene en el hombre-empresa de la biopolítica neoliberal su más novedosa expresión; b) que las formas de esta transformación se relacionan históricamente por modalidades de superposición y no por procesos de clausura, es decir, no se trata simplemente de etapas, sino de líneas de fuerza que interactúan. De hecho, Foucault es el primero en plantear la transformación de estos mecanismos como un proceso de adaptación ${ }^{38}$.

Desde tal perspectiva, un análisis del problema biopolítico en la actualidad, debe centrarse tanto en la biopolítica neoliberal como en las superposiciones que genera respecto a una biopolítica de la razón de Estado, los mecanismos disciplinarios y las disposiciones legales. Me parece que en tal dirección apunta al menos uno de los sentidos de la noción de diagrama.

En las sociedades modernas las dos funciones puras serán la «anatomopolítica» y la «biopolítica», y las dos materias puras, un cuerpo cualquiera y una población cualquiera. El diagrama se podrá, pues, definir de varias maneras que se encadenan: es la presentación de las relaciones de fuerzas propias de una formación; la distribución de los poderes de afectar y de los poderes de ser afectado; la mezcla de las puras funciones no formalizadas y de las puras materias no formadas. ${ }^{39}$

38 "...es como si el poder que tenía como modalidad, como esquema organizativo, la soberanía, se hubiera visto incapaz de regir el cuerpo económico y político de una sociedad entrada en una fase de explosión demográfica y de industrialización, de modo que a la vieja mecánica del poder escapaban muchas cosas... Para recuperar lo particular tuvo lugar una primera adaptación de los mecanismos de poder, dirigida a la vigilancia y el adiestramiento. Nace así la disciplina. Ese fue el proceso de adaptación más fácil. Por eso, entre los siglos XVII y XVIII, fue el primero realizado... Después, a fines del XVIII, hay una segunda adaptación, pero esta vez de fenómenos globales, de población, de procesos biológicos, específicos de la masa humana. Por supuesto, fue una adaptación mucho más difícil, porque implicaba órganos complejos de coordinación y centralización". FOUCAULT, Michel. Genealogía del Racismo. Op. Cit. Pág. 201-202.

39 DELEUZE, Gilles. Foucault. Trad. José Vásquez. Paidós. Barcelona-Buenos Aires. 1987. p. 102. 
El diagrama indica la superposición de estas "lógicas puras", que Deleuze llama aquí funciones puras, con sus consecuentes efectos sobre las materias puras, cuerpo y población. Pero además, las tensiones de fuerza que permiten una distribución particular de los poderes de afectar y de ser afectados.

El diagrama permite entender que, en el presente, se montan elementos disciplinarios, y que se montan sobre procesos de libre circulación con regulaciones generales -a veces globales-, que implican una gestión social de la libertad, a la vez que procesos de coacción permanentes. Esto implica asumir que no existe un paradigma biopolítico único capaz de dar cuenta de la actualidad; sino montajes de lógicas y tecnologías diversas, que en efecto, albergan ciertos conflictos entre sí, pero que interactúan, y que tal diagrama incluye no sólo las prácticas de los 'poderes centrales'; sino también, los procesos de subjetivación que tensionan el interior del diagrama y que no permiten que se solidifique completamente. A la vez, las relaciones de los poderes con tales procesos, que combinan efectivamente tradicionales formas de coacción y castigo, con nuevas formas de gestión de la libertad, de los espacios vitales, y de neutralización inmunitaria.

Hay de hecho en la actualidad, cierto efecto de encierro, ciertas formas de gran encierro, o -lo que es lo mismo- ciertas proyecciones de la sociedad disciplinaria, que en efecto, aparecen como nuevos panoptismos retecnologizados, y más sofisticadas formas de vigilancia ${ }^{40}$.

40 Me parece que la propuesta general de Agamben sobre el campo de concentración como paradigma biopolítico de la actualidad, muestra justamente cómo a partir de los procedimientos jurídicos del estado de excepción, se prolongan formas altamente disciplinarias en las realidades actuales. En cierto sentido, la propuesta de Hardt y Negri de entender los procesos de mundialización bajo la figura de la sociedad mundial de control como Imperio, también muestra que tal proceso de mundialización puede ser concebido como un gran encierro. No obstante, me parece que a la vez que reconocer la sofisticación de las disciplinas en la actualidad, conviene tener en cuenta lo específico de las nuevas formas de poder, en el contexto de las democracias neoliberales. Y tal especificidad no es sólo el refinamiento de la sociedad disciplinaria; sino la superposición de lo legal, lo disciplinario y las tecnologías de seguridad y regulación. De este modo, lo que Agamben y 
También es cierto, que muchas formas de fascistización policial van y vienen, se transforman, encuentran defensores sociales y políticos, y que huellas diversas - desde jurídicas a comunicacionales- reviven formas de totalitarismo. Ninguna de estas cosas son sólo recuerdos, vestigios, o fantasmas, sino elementos activos -dispositivos en muchos casos- engarzados en las conductas de los sujetos, en los sistemas educacionales, en las constituciones políticas, en los aparatos de represión. Por otra parte, resulta evidente la existencia y efectividad del homo œeconomicus neoliberal, bajo la forma del hombre-empresa, que presentaba Foucault, y las formas especialmente sutiles, pero tremendamente efectivas de sujeción que implican los sistemas de endeudamiento, capitalización individual y el juego económico en su conjunto.

Me parece que en este punto resulta nuevamente ilustrativo ejemplificar a partir de la experiencia chilena. Es bastante conocida la relación en principio paradójica, entre neoliberalismo, dictadura, y gobiernos post-dictadura en Chile. Sólo quisiera poner sobre la discusión algunos aspectos que, según me parece, grafican la forma del diagrama como método de análisis. Un primer elemento clave es la instalación de políticas neoliberales a partir de 1975. Constituyen un verdadero "tratamiento de shock" a la economía chilena, según la expresión de Friedman. Una serie de enormes intervenciones políticas son llevadas

Negri efectivamente muestran, que es la íntima relación entre democracias neoliberales, sociedad disciplinaria y totalitarismo, queda comprendido en un nuevo diagrama. Dicho de otro modo, no son homologables las democracias neoliberales y los totalitarismos, pero tienen relaciones íntimas, que pueden ser leídas justamente a partir de la superposición de las lógicas de poder. Por lo tanto requiere pensarse el diagrama que las superpone y las relaciona. Pensar las democracias neoliberales sólo como una sofisticación disciplinaria de los totalitarismos, es insuficiente pues pierde de vista lo específico del ejercicio del poder en las democracias neoliberales, se trata de una crítica a destiempo, y en tal empeño es más fácil perder el rumbo. Por el contrario, la noción de diagrama nos permite reorientar el análisis a lo específico de las democracias neoliberales actuales. Esto implica reconocer dos cosas a la vez: primero, que no son lo mismo, ni en forma metafórica ni histórica; segundo, que a pesar de sus diferencias tienen relaciones íntimas, al punto que estas formas de democracia no son posibles sin un activo componente autoritario, y disciplinario, aunque su eje es el dispositivo económico. 
a cabo, intervenciones que difícilmente podrían ser implementadas en condiciones democráticas, pues generan una gran conmoción social: reducción fiscal a partir de recorte presupuestario no selectivo, es decir proporcional a las distintas reparticiones del Estado, con un especial acento en la reducción de funcionarios públicos. Devaluación de la moneda con el cambio del escudo al peso. Liberalización monetaria, orientada a la libre fijación del precio del dólar con tendencia alcista. Orientación a la diversificación de exportaciones y a la privatización de empresas públicas, entre los aspectos más importantes.

Además de estas primeras transformaciones, encontramos, a comienzos de la década de los ochenta, los primeros pasos de reconversión del sistema social a un mercado de capitalización individual, como es el caso de las administradoras de fondos de pensiones (AFP). Se trata quizás del paso más importante, pues generará dos efectos: por una parte extenderá la racionalidad de mercado al sistema social. Es decir, recompondrá la relación con las pensiones, a un mercado con proveedores de servicios de administración financiera, por una parte y clientes, de la otra. Ya no se tratará, entonces, de un sistema de pensiones peor o mejor, a nivel nacional; sino de servicios privados ofrecidos de manera individual, con lo cual el Estado, más allá de ciertas labores de regulación, deja atrás la tarea de estructurar un sistema nacional de pensiones de calidad, y velar por el derecho de los ciudadanos a una pensión. Desde ese momento, el problema de la pensión será un problema entre privados. Una mala o buena pensión, será el resultado de un mal negocio, una mala o buena decisión de cada cual. El segundo efecto importante es que permite el refuerzo del mercado financiero a partir de una gran liquidez del sector privado. En efecto, las administradoras de fondos de pensiones no serán ni cooperativas, ni pequeñas asociaciones que inviertan en la industria, sino grupos económicos que invierten en el mercado bursátil. Por lo tanto el efecto económico buscado no es, por ejemplo, la creación de empleo que se explicaría con la inversión en industria; sino fomentar la capacidad de inversión de los grandes conglomerados privados, a través de la incorporación de siete millones de cotizantes que mes 
a mes ingresan capital y entregan liquidez y capacidad de inversión a estos conglomerados privados. Este primer paso, de las AFP, será complementado con otros dos pasos fundamentales, que es la reforma al sistema de salud y finalmente al sistema educacional. La dirección es relativamente la misma en ambos casos, primero un efecto de reducción y desconcentración de la gestión. Es decir, un porcentaje menor de la población permanecerá en sistemas públicos de salud y educación, y este porcentaje reducido se gestionará localmente a través de los municipios, para escuelas y consultorios, o por los servicios de salud locales en el caso de los hospitales. El segundo efecto es igual que en el caso anterior, es decir, la formación de un mercado de salud y educación. El efecto general es la eliminación de sistemas nacionales de salud, educación y pensiones, y la generación de sistemas de capitalización individual, para la cobertura de estos nuevos mercados. De este modo, se elimina toda consideración estructural del sistema social que será atomizado en diversos servicios transables a nivel individual. Evidentemente esto genera una serie de transformaciones económicas con efectos discutibles; tales discusiones nos alejarían del objeto que nos ocupa, y por lo regular tienden a reducir la discusión política a tecnicismos económicos. Pero quisiera comentar un asunto que suele no tomarse en cuenta en tales tecnicismos: me refiero a los efectos sociales que se generan a partir de la implementación de tales mecanismos de capitalización individual, a través de los cuales el sistema social es invadido por la racionalidad de mercado. Con 'efectos sociales' no me refiero al aumento o disminución de la pobreza, asunto fluctuante, y que es uno de los efectos que de hecho se toman en cuenta, se miden, se explican, etc. Me refiero a un efecto estructural. Con esta atomización del sistema social en servicios individuales de pago directo, como las instituciones de salud previsionales (Isapres) o bajo el modelo de pago del outsourcing, en el caso de las escuelas y liceos, se produce un efecto de desintegración de los servicios, una suerte de tendencia tecno-anárquica del comportamiento general de tales servicios. Me explico. Si ya no hay un sistema de salud integrado, sino, al contrario, múltiples servicios de salud, que funcionan cada cual con diversos modelos de negocios, características institucionales y rangos 
de calidad diversos; entonces ya no será posible implementar políticas generales, ni de inversión, ni de prioridades sanitarias, ni de estándares de calidad generales; pues todo esto obedece o a decisiones propias de las unidades de negocios, o a resultados de sus gestiones. Por lo cual ya no hay avance o retroceso del sistema general de salud, sino sólo de tal o cual servicio, o de tal o cual Isapre. Por lo tanto, podemos encontrar un consultorio de atención primaria, en una comuna bien gestionada o con mayores recursos, que logra un estándar de calidad aceptable, y a la vez, otro consultorio, bajo el mismo régimen jurídico, en una comuna con recursos escasos y resultados muy por debajo del primer consultorio. A su vez, podemos encontrar no sólo Isapres de buena o mala calidad; sino que al interior de cada isapre, planes de salud de primera, segunda, tercera, o cuarta categoría. Este mismo esquema puede trasladarse al ámbito de las escuelas, que ya he analizado anteriormente. Es decir, se instala la lógica de la desigualdad, de la segmentación social, y del ascenso social individual. Ya no hay avances sociales nacionales, sino ascenso social de los individuos. Por graficarlo de una manera popular: "los barrios se echan a perder". Un barrio ya no accede a mejores servicios, ni ve mejoras generalizadas; el barrio "no mejora", sino que algunos individuos del barrio mejoran, contratan un mejor colegio, una mejor isapre, finalmente se cambian de barrio. El efecto social al que me refiero es la imposibilidad del avance social colectivo. Se trata de un efecto estructural, no se modifica al mover la línea de la pobreza dos puntos hacia arriba o hacia abajo; tampoco es producto del azar o la naturaleza desigual de las personas, sino un efecto de medidas políticas; se trata de una desigualdad provocada. Aquí conviene volver a mirar el análisis de Foucault, y es que a principios de la década de los ochenta, en Chile, se generaron, mediante una intervención política, las condiciones para el desarrollo del tipo de unidad económica que Foucault presentaba como dispositivo biopolítico clave del neoliberalismo, es decir, las condiciones del hombre-empresa, a través de la generación de un mercado vital (el entrelazado de varios mercados: educación, salud, pensiones) y la condición estructural de desigualdad, como motor básico del ascenso social y la inversión sobre sí mismo. 
Ahora bien, el asunto clave del ejemplo es la relación entre dictadura, democracia y neoliberalismo. Mucho se ha dicho que los gobiernos de postdictadura, digamos derechamente concertacionistas, han sido continuadores de la dictadura en la mantención del modelo neoliberal. Me parece que aquello es irrefutable. De hecho, un análisis desinteresado, debería decir que no sólo hay continuidad, sino profundización del modelo, casi sin correcciones, fuera de ciertos reparos aquí y allá; pero incluso tales reparos con medidas de inspiración neoliberal. En términos generales el asunto ha pendulado de una concepción neoliberal norteamericana dogmática y tecnicista, a ciertos matices de una concepción neoliberal alemana, algo más integral y más política. La estructura, sin embargo, se mantiene. ¿Cuál es la diferencia entonces? Siempre se puede decir que la actual democracia es lo mismo que la dictadura, que la concertación no es más que pinochetismo, etc. Evidentemente esto no es razonable. Analicemos el asunto en términos de diagrama biopolítico.

Los componentes del diagrama son básicamente los mismos. Poder soberano, es decir, una forma de poder jurídico y territorial. Una serie de dispositivos disciplinarios, con sus consecuentes procesos de individuación, normalización, castigo, una anatomopolítica de los cuerpos. A la vez que una tanatopolítica, una política de la muerte que mezcla los rasgos del poder soberano -el poder de dar muerte- con los dispositivos de seguridad, propios de la biopolítica y los argumentos de la razón de Estado. Finalmente una biopolítica de regulaciones generales, que no administra la muerte, sino que hipoteca la vida al juego económico. Los componentes del diagrama, insisto, son básicamente los mismos, y sin embargo cambia la composición de fuerzas de los mismos. La íntima solidaridad entre dictadura y democracia neoliberal pasa por la historicidad de estas líneas de fuerza.

De este modo, la democracia neoliberal profundiza el carácter biopolítico de cuño gubernamental, que se transforma en el rasgo principal del ejercicio de poder sobre la vida pero en la trama histórica lo hace funcionar con sistemas de represión focalizados, no tan extendidos como la tanatopolítica totalitaria de la dictadura; no tan estructurales, 
pero, por lo mismo, más invisibles para la población en su conjunto. La represión focalizada vuelve inmune a quien no la padece. La historia del conflicto mapuche puede ser la expresión más evidente de esta tanatopolítica, pues incluye no sólo prácticas disciplinarias, de castigo, tortura, censura o aplicación de aparatos jurídicos de excepción, como la ley antiterrorista, sino que incluye un rasgo racial y de soberanía. Todos ellos, elementos claves en la biopolítica totalitaria.

Pero además de este tipo de rasgos fácilmente denunciables por su semejanza histórica con diversos procedimientos de la dictadura, surgen nuevas formas de disciplinamiento y de vigilancia, asociadas con los procesos de la segmentación social y la desigualdad estructural. No sólo los individuos ascienden o descienden socialmente, sino que se genera una espacialidad dividida, de la cual se vuelve testigo privilegiado la ciudad. Una ciudad dividida en territorios; en la que encontramos, al mismo tiempo, una ciudad de la libre circulación, con acceso a servicios y situación de bienestar y una segunda ciudad, precarizada, donde se difuminan las regulaciones y normas sociales del territorio liberal y resulta siendo administrada bajo una lógica cada vez más claramente policial, ya a través de procesos de disciplinamiento y castigo, ya a través de la estigmatización como herramienta policial.

De este modo, lo que encontramos, no es la lógica pura de la racionalidad neoliberal y sus regulaciones económicas, sino, tal lógica instalada sobre formas estructurales de carácter totalitario, como el juego de los estados de excepción, las prácticas represivas en los lugares clásicos de la sociedad disciplinaria, la escuela, el trabajo y la segmentación social como estructura básica de vigilancia. El diagrama, entonces, muestra la superposición de estos mecanismos diversos que incluye ciertas pugnas entre los mismos, y que va asumiendo matices distintivos, según ciertas contingencias. De tal modo que un ministro del Interior adoptará prácticas más represivas y otro, más bien inmunitarias. Un programa de política pública se inclina más por la redistribución estructural de la riqueza, y otro, por el contrario, a los subsidios y bonos individuales. Una agencia gubernamental optará por el tratamiento técnico de las reivindicaciones de tal o cual grupo 
social, con mayor participación y diálogo; mientras otra diseñará, con "grupos de expertos", programas para aplicar a grupos sociales, sin ninguna participación de los mismos. Estas modalidades diagramáticas, en efecto, se dan en la actualidad en las diversas democracias neoliberales con modulaciones y pugnas internas, pero manteniendo el carácter estructural dominante en términos de una racionalidad política neoliberal, o gubernamentalizada.

\section{Palabras Finales}

Los elementos descritos en este artículo entregan la posibilidad de concluir en dos direcciones que, siguiendo relativamente el lenguaje deleuziano, podemos considerar macropolíticas y micropolíticas. Es decir, que refieren a las consideraciones estructurales de las transformaciones políticas: los sistemas políticos, las formas de representación, los aparatos jurídicos, los modelos de gestión del sistema social, entre otros elementos importantes de lo que podemos considerar como macropolítica. La segunda dirección apunta a los modos de vida de los sujetos, sus maneras de asociación, las pautas de construcción de sí mismo, sus procesos de lucha, los cambios de dirección en las maneras de autoconcebirse, pensarse, sentirse, soñarse, o llevarse a cabo. En cierto sentido, el gran descubrimiento político de Deleuze y también de Foucault, es reconocer que lo que tradicionalmente se había considerado "privado" es también una forma de política. Es decir, que las relaciones de pareja, las formas de vida en común, los roles al interior de la familia, las identidades de género, los estigmas sociales, las ideas de normalidad, son también ámbitos políticos. No pretendo entregar conclusiones taxativas ni en uno ni en otro ámbito; pero quisiera destacar para ambos, algunos elementos que me parecen claves para concluir o tomar decisiones.

En primer lugar y respecto al nivel macropolítico, me parece que el punto más importante es quitar el foco de atención del problema del Estado. Si, en efecto, el diagrama político implica superposiciones, pero en tales superposiciones hay una hegemonía de la lógica neoliberal, 
entonces resulta evidente que la denuncia al Estado, no es el asunto principal. El Estado es el centro del poder en las sociedades disciplinarias, y en los totalitarismos que actúan bajo la razón de Estado. Pero no es el caso de la racionalidad neoliberal. Si revisamos este asunto, la verdad es que la racionalidad neoliberal ha abogado permanentemente por la minimización del Estado y por su gubernamentalización. Es decir, por la extensión de la racionalidad de mercado al orden estatal. Si bien es cierto que los componentes represivos y disciplinarios siguen vinculados fuertemente al Estado, éste no es el eje principal del diagrama. Por el contrario, tenemos un Estado que cada vez gobierna menos en razón de propósitos propios y cada vez más para el mercado. El eje del diagrama, es justamente la extensión de la racionalidad de mercado a todos los ámbitos sociales, y en tal extensión se descentralizan las formas de poder. La extensión de esta racionalidad no es patrimonio del Estado, y ha dejado de ser sólo un dato económico. Gobierna las familias, las decisiones personales, las instituciones gubernamentales, los conglomerados políticos, las instituciones religiosas, las actividades deportivas. Se trata entonces de una racionalidad política, es decir, un elemento mucho más abstracto que una institución, un sujeto o una serie de sujetos, aun cuando la actividad que genera tienda al beneficio de sujetos bastante particulares. Incluso, cuando para la racionalidad general estos sujetos sean desechables. El problema de clase, tradicional, en cierto sentido se reformula. Por una parte, sigue vigente el mecanismo tradicional de reproducción de clase, porque es funcional para las clases privilegiadas, y la posición de privilegio sigue siendo una posición a mantener. Pero esto no es inherente a la racionalidad neoliberal, sino la lógica del enriquecimiento. Es decir, la racionalidad política neoliberal es fundamentalmente expansiva: busca en primer lugar el enriquecimiento permanente, el crecimiento constante. Si las viejas clases privilegiadas, son sustituidas o no por otras, resulta un dato irrelevante para tal racionalidad, mientras se produzca enriquecimiento. El problema, entonces, no es fundamentalmente mantener, o reproducir, sino enriquecerse y crecer. Me parece, entonces, que el problema macropolítico no pasa por un proyecto crítico dirigido al Estado, sino por reanudar un proyecto de crítica a 
la economía política, que los mismos economistas, y desde luego los filósofos, han abandonado casi por completo.

Respecto a lo micropolítico. El diagrama de las democracias neoliberales se presenta como una nueva forma de poder sobre la vida, que transforma a ésta en un dato económico, y que genera un tipo especial de sujeto, que articula su vida en torno a lo económico. Lo hace a través de la generación de un mercado vital, como he expuesto. Pero también a través de una nueva relación con "lo verdadero" y lo "utópico". En efecto, el neoliberalismo así entendido, no es una ideología, en el sentido que su relación con "lo verdadero" no es una relación de encubrimiento, maquillaje o mala conciencia. Foucault califica esta particularidad como la de un régimen de veridicción. Esto no implica desechar los elementos ideológicos, sino reformular el problema de la ideología. ¿Qué es un régimen de verdad o veridicción, en este contexto? No la forma en que se expresa un error, una mentira o una ilusión, es decir, no la forma en que una mentira llega a presentarse como verdad, sino el cruce de ciertas prácticas y discursos que constituyen e instalan una verdad. No una apariencia de verdad, sino todo lo contrario. La potencia de un régimen de veracidad consiste en que tiene la capacidad de generar realidad. $Y$ de hecho genera no sólo un tipo de verdad pragmática o técnica, sino una particular forma de verdad utópica. En términos biopolíticos, el modelo del hombre-empresa se basa sobre ciertas promesas, un proyecto, un sueño de sí. Este proyecto, al menos alguna vez, llega a realizarse. Si el proyecto del hombre empresa fuese falso, perdería gran parte de su potencial como motor económico. El elemento fundamental del hombre-empresa como proyecto de vida, es que resulta verificable, es decir, por lo menos para algunos de los que viven bajo la forma del hombre empresario de sí mismo, el ideal llega a realizarse, se transforma en un self-made, un hombre hecho por sí mismo, en base a su propio esfuerzo e inversión. Alcanza a través de esta característica un potencial utópico, sin el cual sería imposible, a pesar de todas las coacciones, generar un mercado vital lucrativo. Es cierto que podría mostrarse que esto efectivamente funciona para 
algunos, y no para cualquiera; que la condición de clase, o como quiera plantearse, pone las condiciones básicas de la meritocracia del hombre-empresa; pero también es cierto que puede mostrarse lo contrario y se muestra a diario. En cierto sentido, una utopía verificable es incontestable, tiene la capacidad de desactivar cualquier discurso crítico, porque no es ni discursiva, ni empírica, ni imaginaria, sino una imagen social simple, que constituye una de las formas de verdad en este particular régimen de veridicción. Por tal razón es posible, por ejemplo, presentar un discurso crítico, con objetivo emancipatorio sobre la estratificación escolar, como crónica de los futuros de desigualdad anunciados y cargarlo de empiria estadística; pero la promesa del ascenso individual, como refuerzo de las metas sociales, habla en una empiria de un tipo muy distinto. De este modo, el potencial de lucha o de subjetivación en términos micropolíticos, o éticos -si quiere pensarse de este modo- requiere también una reformulación discursiva. Todo proyecto de construcción de sí mismo, todo proyecto de vida -por decirlo en un lenguaje popular- está condicionado ya previamente por este proyecto vital, la forma empresa amenaza con apoderarse de la vida de todos los que vivimos en democracias neoliberales. Todo proyecto de construcción de sí mismo, debe o aceptar la forma empresa o resistir a ella, aunque esto sea especialmente difícil. En cierto sentido, la reflexión que aporte a desactivar tal efecto de apropiación sobre la vida, me parece el mayor desafío de una ética contemporánea.

\section{Bibliografía}

CASTRO, Edgardo. Biopolítica: De la Soberanía al Gobierno. En Revista Latinoamericana de Filosofía, Vol. XXXIV. № 2. Primavera 2008.

DELEUZE, Gilles. Foucault. Trad. José Vásquez. Paidós. Barcelona-Buenos Aires. 1987.

DELEUZE, Gilles. Post-scriptum sobre las sociedades de control. En DELEUZE, Gilles. Conversaciones. Trad. José Luis Pardo. Pretextos. Valencia. 1996.

DELEUZE, Gilles. ¿Qué es un acto de creación? En DELEUZE, Gilles. Dos regímenes de locos. Trad. José Luis Pardo. Pre-textos. Valencia. 2008. 
FOUCAULT, Michel. El nacimiento de la biopolítica. Trad. Horacio Pons. Fondo de Cultura Económica. Buenos Aires, Argentina. 2007.

FOUCAULT, Michel. Genealogía del Racismo. Trad. Alfredo Tzveibel. Altamira. La Plata, Argentina. 2001.

FOUCAULT, Michel. La verdad y las formas jurídicas. Trad. Enrique Lynch. Gedisa. Barcelona. 1996.

FOUCAULT, Michel. Nacimiento de la Medicina Social. En Estrategias de Poder, Obras esenciales, Volumen II. Trad. Fernando Álvarez Uría, Julia Varela. Paidós. Barcelona-Buenos Aires-México. 1999.

FOUCAULT, Michel. Seguridad, Territorio, Población. Fondo de Cultura Económica, Buenos Aires, Argentina. 2006.

FOUCAULT, Michel. Vigilar y Castigar. Nacimiento de la Prisión. Trad. Aurelio Garzón del Camino. Siglo XXI. Buenos Aires. 1976. $1^{\text {a }}$ Reimpresión. 2002.

FRIEDMAN, Milton. FRIEDMAN, Rose. TWO LUCKY PEOPLE: MEMOIRS. University of Chicago Press. Chicago-London 1999.

SALINAS, Adán. El campo de concentración. Una aproximación crítica a la propuesta de Giorgio Agamben. Investigación para optar al grado de Master en estudios avanzados en filosofía. Universidad Complutense de Madrid. 2011.

SALINAS, Adán. Usos y Transformaciones del concepto biopolítica en los trabajos de Michel Foucault. 1973-1979. Tesis para optar al grado de Magíster en Filosofía, con mención en filosofía moral y política. Universidad de Chile. 2010. 